\title{
0 BRIX NA DETERMINAÇÃO DA RIQUEZA EM AÇÚCARES DO MAMÃO COMO AUXILIAR NO MELHORAMENTO DO MAMOEIRO (Carica papaya L.)
}

\author{
OCTAVIO VALSECHI \\ Livre Docente da Seç̧ão de Tecnologia Agrícola \\ E. S. A. "Luiz de Queiroz" \\ JOSE' MITIDIERI \\ Assistente da Secção de Genética \\ E. S. A. "Luiz de Queiroz"
}

INDICE

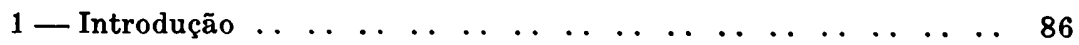

2-Material e Métodos ... . . . . . . . . . . . . . . . . . . . $\quad 86$

3 - Resultados obtidos . . . . . . . . . . . . . . . . . . . . . 88

4 - Discussão $\ldots \ldots \ldots \ldots$

5 - Resumo e Conclusões . . . . . . . . . . . . . . . . . . . . . 91

6 - Summary and Conclusion . . . . . . . . . . . . . . . 91

7 - Agradecimentos $\ldots \ldots \ldots \ldots$

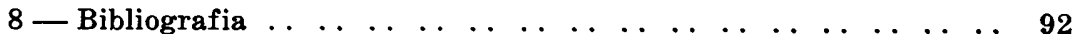




\section{1 - INTRODUÇÄO}

Entre outras qualidades do fruto do mamoeiro, sem dúvida, a doçura é um fator preponderante a ser levado em linha de conta nos trabalhos de melhoramento.

O critério seguido para êste ponto de vista tem sido o da classificação gustativa. Este processo, apesar de ser um auxiliar precioso, apresenta os inconvenientes das varições pessoais, além de não precisar a riqueza percentual em açúcares do fruto. Interessante seria a determinação química dos açúcares que passaria a ser elemento básico na classificação, não se dispensando, é obvio, o critério gustativo como auxiliar, uma vez que êste último pode propiciar ao melhorista qualidades não reveladas pela análise química dos açúcares do fruto.

Entretanto, a análise química, quando se trata de trabalho de melhoramento é pràticamente inexequível pelo grande número de frutos a examinar. Por essa razão ter-se-ia que procurar na prática um outro modo fácil e rápido que proporcionasse ao melhorista aquelas indicações. $E$ ' isto, aliás, o que se faz com o melão e a melancia conforme trabalhos de PARRIS (1949), de PORTER, BISSON e ALLINGER (1940) e de DAVIS e WHITAKER (1942) uma vez que se sabe haver para tais frutos uma correlação positiva e significante entre os seus sólidos totais, fàcilmente determinados pelo refratómetro de campo e a sua percentagem de açúcares.

O presente trabalho desenvolveu-se no sentido de se verificar se o método usado para aquelas frutas também se aplicava para o caso do mamão.

\section{2 - MATERIAL E METODOS}

Os frutos utilizados na presente verificação foram em número de 50 e de procedências diversas. Com isso visaram os autores uma maior generalização dos resultados obtidos.

2.1. - Colheita - De plantas prèviamente conhecidas para os futuros trabalhos de melhoramento efetuou-se a colheita de frutcs que se apresentavam no "estado de vez". A maturação era em seguida completada à sombra.

2.2 - Tirada de Amostra - Uma vez maduro, o fruto era descascado, aberto para a retirada das sementes e pôsto em liquidificador. Resultava daí um líquido expesso integralmente 
homogeneisado de onde se retiravam as amostras para as respectivas análises.

\section{3 - Métodos Físicos e Químicos de Análises.}

2.3.1. - Brix - A determinação dos sólidos totais foi feita por intermédio do refratómetro de campo Zeiss, com uma gota do líquido preparado como em 2.2 .

2.3.2. - Açúcares totais - Os açúcares foram determinados segundo o método de Norris, modificado por Leme Junior (não publicado) para a determinação em frutas, usando-se o vaso de Bohemia ao em vez do aparelhamento recomendado por aquele autor. As técnicas seguidas foram as seguintes:

I) Tomar um vaso de Bohemia de $500 \mathrm{ml}$ limpo e sêco. Tarar. Seja T. esta tara.

II) No mesmo pesar $50 \mathrm{~g}$ do material desintegrado e homogeneisado.

III) Adicionar ao mesmo cêrca de $400 \mathrm{ml}$ de água e hidróxido de bário a $5 \%$, até neutralidade ao tournesol.

IV) Ferver moderadamente durante uma hora, agitando com um bastonete. Retirar êste do vaso, lavando-o. Restabelecer o volume inicial com água e deixar ferver por mais 10 minutos.

V) Esfriar. Enxugar bem o exterior do vaso e pesar. Seja $P$ o pêso total.

VI) Filtrar em algodão.

VII) Verificar no filtrado o Brix, com o Refratómetro Zeiss de campo. Seja $b$.

VIII) Passar $100 \mathrm{ml}$ do filtrado para um balão de $200 \mathrm{ml}$. Tratar com acetato de chumbo a $54^{\circ}$ Brix até precipitar as impurezas. Eliminar o excesso de chumbo com a mistura em partes iguais de fosfato bissódico a $7 \%$ e oxalato de potássio a $3 \%$. Completar o volume com água. Filtrar abandonando as primeiras porções do filtrado.

IX) Tomar $50 \mathrm{ml}$ do filtrado em balão de $100 \mathrm{ml}$ e inverter com $5 \mathrm{ml}$ de ácido clorídrico concentrado, densidade igual a 1,19 aquecendo em banho-maria, a $67-70^{\circ} \mathrm{C}$ por 5 minutos.

X) Esfriar, neutralizar com hidróxido de sódio concentrado, em presença do papel de tournesol. Esfriar de novo e completar o volume. Filtrar. 
XI) No filtrado determinar os açúcares redutores segundo as técnicas indicadas por EYNON e LANE (1913) usando solução de azul de metileno como indicador Seja $\mathrm{N}$ o número de $\mathrm{ml}$ gastos.

XII) Determinar à parte, no material homogeneisado, a percentagem de fibra segundo A. O. A $r$ (1945). Seja F a percentagem de fibra.

XIII) A percentagem $x$ de açúcares totais, expressa em glucose será dada pela fórmula:

$$
x=\frac{20(P-T-\stackrel{F}{2})}{50(1+0,004 b) N} .
$$

2.4. - Métodos Estatísticos - Os métodos estatísticos utilizados baseiam-se nos processos correntes de análise estatística, tais como os recomedados por KENNEY (1939). Nos cálculos também foram utilizadas as tabelas de BRIEGER (1937).

\section{3 - RESULTADOS OBTIDOS}

Os resultados obtidos na presente investigação acham-se sintetisados no quadro I. Estes foram estudados estatisticamente obtendo-se os valores de 9,482 e de 5,422 para as médias de brix refratométrico e de açúcares totais expressos em glucose, com os respectivos erros padrões de $\pm 1,2410$ e de $\pm 0,7565$. Correlacionando-se o valor de brix com o de açúcar total de cada amostra verifica-se que entre os mesmos existe uma forte correlação linear, e positiva cujo $r=0,87$, é significativo ao nível de $1 \%$. Logo o açúcar total varia no mesmo sentido dos sólidos, o que pode ser fàcilmente calculado se considerarmos o coeficiente de regressão " $b$ " dado pela fórmula:

$\mathrm{b}=\frac{\sigma_{\mathrm{a}}{ }^{2}-\sigma_{\mathrm{s}}^{2}+\sqrt{\left(\sigma \mathrm{a}^{2}-\sigma \mathrm{s}^{2}\right)^{2}+4 \mathrm{r}^{2} \sigma_{\mathrm{a}}{ }^{2} \sigma_{\mathrm{s}}{ }^{2}}}{2 \mathrm{r} \sigma_{\mathrm{a}} \sigma_{\mathrm{s}}}$

na qual " $a$ " representa os açúcares totais, " $s$ " os sólidos pelo brix refratométrico e " $\mathrm{r}$ " o coeficiente de regressão. 
Temos portanto:

$b=\frac{0,5723-1,5402+\sqrt{(0,5723}-1,5402)^{2}+4<0,7569 \times 0,5723 \times 1,5402}{2<0,87 \therefore 0,7565 \div 1,2410}$,

uma vez que :

$$
\begin{aligned}
\sigma \mathrm{a} & =0,7565 \text { e portanto: } & \text { oa } 2 & =0,5723 ; \\
\sigma \mathrm{s} & =1,2410 \text { e portanto: } & \sigma \mathrm{s} 2 & =1,5402 ; \\
\mathrm{r} & =0,87 \text { e portanto: } & \mathrm{r} 2 & =0,7569 .
\end{aligned}
$$

Então :

$\mathrm{b}=0,5699$.

Mas como, na equação da reta temos :

$\mathrm{a}-\overline{\mathrm{a}}=\mathrm{b}(\mathrm{s}-\overline{\mathrm{s}})$

em que "s" e "a", representam respectivamente as médias de sólidos e de açúcares, teremos:
$\mathrm{a}-5,422=0,5699(\mathrm{~s}-9,482)$.
$\mathrm{a}=0,5699 \mathrm{~s}-5,4038+5,4220$.
$\mathrm{a}=0,5699 \mathrm{~s}-0,0182$.

Ou seja :

$$
\mathrm{a}=0,57 \mathrm{~s}
$$

que é a reta de regressão procurada. 


\section{QUADRO I}

Brix-Médio e açúcares totais obtidos em cinquenta frutos

\begin{tabular}{|c|c|c|c|c|c|}
\hline $\begin{array}{c}\text { N. da } \\
\text { Amostra }\end{array}$ & Brix & Aç. Totais & $\begin{array}{c}\text { N. da } \\
\text { Amostra }\end{array}$ & Brix & Aç. Totais \\
\hline $\begin{array}{r}1 \\
2 \\
3 \\
4 \\
5 \\
6 \\
7 \\
8 \\
9 \\
10 \\
11 \\
12 \\
13 \\
14 \\
15 \\
16 \\
17 \\
18 \\
19 \\
20 \\
21 \\
22 \\
23 \\
24 \\
25\end{array}$ & $\begin{array}{r}10,5 \\
10,0 \\
8,7 \\
11,0 \\
11,0 \\
9,0 \\
11,0 \\
9,5 \\
9,8 \\
9,5 \\
9,3 \\
10,5 \\
9,5 \\
9,6 \\
11,5 \\
12,5 \\
10,5 \\
10,0 \\
12,0 \\
11,5 \\
9,5 \\
9,5 \\
9,8 \\
8,3 \\
9,5\end{array}$ & $\begin{array}{l}5,82 \\
6,03 \\
5,49 \\
6,29 \\
6,13 \\
4,45 \\
6,12 \\
5,67 \\
6,05 \\
5,81 \\
5,46 \\
6,04 \\
5,92 \\
5,35 \\
6,06 \\
6,46 \\
5,49 \\
5,95 \\
6,89 \\
6,83 \\
6,03 \\
5,36 \\
5,94 \\
4,86 \\
5,30\end{array}$ & $\begin{array}{l}26 \\
27 \\
28 \\
29 \\
30 \\
31 \\
32 \\
33 \\
34 \\
35 \\
36 \\
37 \\
38 \\
39 \\
40 \\
41 \\
42 \\
43 \\
44 \\
45 \\
46 \\
47 \\
48 \\
49 \\
50\end{array}$ & $\begin{array}{r}9,2 \\
9,0 \\
9,0 \\
9,7 \\
8,2 \\
7,8 \\
7,4 \\
7,0 \\
11,0 \\
10,8 \\
8,6 \\
9,0 \\
7,5 \\
8,8 \\
9,5 \\
7,8 \\
9,5 \\
8,4 \\
9,4 \\
8,2 \\
8,5 \\
11,2 \\
7,8 \\
8,5 \\
8,8\end{array}$ & $\begin{array}{l}4,81 \\
5,57 \\
5,85 \\
5,43 \\
4,78 \\
4,43 \\
4,32 \\
3,90 \\
6,48 \\
6,34 \\
5,04 \\
5,37 \\
4,51 \\
5,22 \\
5,43 \\
4,37 \\
5,61 \\
4,77 \\
5,66 \\
4,90 \\
4,03 \\
5,59 \\
3,69 \\
4,49 \\
4,73\end{array}$ \\
\hline
\end{tabular}

\section{4 - DISCUSSÃO}

Considerando-se o que acima ficou exposto pode-se verificar que nos trabalhos de melhoramento do mamoeiro é possivel racionalizar-se o critério da seleção de frutos em relação ao seu conteúdo de açúcares pela simples determinação dos sólidos totais, determinação essa, efetuada com o refratómetro de campo. Dessa forma evitam-se as trabalhosas análises químicas que sem dúvida seriam impraticáveis. E' viável, portanto, para o mamão em relação ao seu teor de açúcares, o processo utilizado na classificação de melões e melancias.

Não se deve entretanto, abandonar o critério gustativo que funcionaria, em última análise, como auxiliar, selecionando os frutos já escolhidos pelo seu maior conteúdo de açúcares, pois, 
êste processo dá ao melhorista os caracteres de palatabilidade do fruto, o que não pode ser determinado, pelo menos dentro dos conhecimentos atuais, pela análise química.

\section{5 - RESUMO E CONCLUSÕES}

$\mathrm{Na}$ presente publicação em vista da falta de um critério a. nálitico fácil e cômodo para a seleção de frutos nos trabalhos de melhoramento do mamoeiro, os autores desenvolveram pesquisas visando a aplicação dos métodos utilizados para o melão e para a melancia, isto é, procuraram verificar se havia correlação entre o teor de sólidos determinados pelo refratómetro de campo e o conteúdo total de açúcares do fruto. Ficou provacio que tal correlação existe sendo ela positiva e significante. Cal-. cularam ainda os autores a equação de uma reta de regressão que possibilita o conhecimento do teor de açúcares totais do fruto pela simples determinação de seu brix refratométrico.

Tal equação é dada pela fórmula :

$\mathrm{a}=0,57 \mathrm{~s}$

na qual "a" e "s" representam, respectivamente, açúcares totais em glucose e sólidos totais.

\section{6 - SUMMARY AND CONCLUSION}

There is in the literature a noteworthy lack of sampling methods to be employed in the selection of papaya fruits for genetical improvement purposes. In the present experiment methods applied to melon and watermelon were extended to papaya with good results. The authors tried to correlate the solids content-as determined by a hand refractometer-with total sugars in the fruit. The correlation does exist being significant and positive. A regression equation was worked out; it permits to calculate the total sugar content provided the Brix value determined by the hand refractometer is known. The equation is as follows :

$\mathrm{a}=0.57 \mathrm{~s}$

where

$\mathrm{a}=$ total amount of sugar as glucose, and

$\mathrm{s}=$ total solids. 


\section{7 - AGRADECIMENTOS}

Desejam os autores deixar aquí consignados seus sinceros agradecimentos ao Eng. Agr. Marcilio Dias, pelas sugestões apresentadas nêste trabalho e aos livres-docentes Drs. José T. do Amaral Gurgel e Dr. Frederico Pimentel Gomes, pela orientação dada na análise estatística.

\section{8 - BIBLIOGRAFIA}

ASSOCIATION OF OFFICIAL AGRICULTURAL CHEMISTS. 1945 - "Official and tentative methods of analysis". 6a Ed. pág. 408-409 - Washington, U.S.A.

BRIEGER, F. G. 1937 - “Tabuas e fómulas para estatística”. 1a. Ed. São Paulo, Brasil.

DAVIS, N. Glen e Thomas Whitaker. 1942 - "Growing andhandling cantaloupes and other melons". Circular 352 do Agriculture Experiments Station. pág. 18-19, Julho -Berkeley, California, U.S.A.

KENNEY, F. Hohn. 1939 - "Mathematics of statistics". 1a. Ed. pág. 141-142. New York. U.S.A.

LANE, J. Enry e Lewis Eynon. 1913 - "Determination of reducing sugars by Fehling's solution with Mehtylene Blue Indicator". Londres, Inglaterra.

LEME JUNIOR, Jorge. Não publicado - "Método de Norris", modificado para determinação de açúcares em frutas.

PARRIS, G. K., "Watermelon Breeding". 1949 - Reprint from Economic Botany, April-June, pág. 196-197. Leesburg, Fla. U.S.A.

PORTER, D. R., C. S. Bisson e H. W. Allinger. 1940 - "Factors affecting the total soluble solids, reducing sugars, and sucrose in Watermelons" - Hilgardia - Vol. 13, n. 2, pág. 3340 - February - California Agriculture Experiment Station. U.S.A.

TRAUB, P. H., T. R. Robinson e H. E. Stevens. 1942 - "Papaya production in the United States". Circular n. $633-$ April, e U. S. Dep. of Agric. U.S.A.

WOLF, H. S. e S. J. Linch. 1950 - "Papaya culture in Florida". Fla. Agr. Exp. Station Bul. Revised in March. U.S.A. 